\title{
PABLO GUADARRAMA: EL PENSAMIENTO POLÍTICO LATINOAMERICANO Y LA CULTURA DE LA PAZ
}

\author{
Carlos Rojas Osorio * \\ Universidad de Puerto Rico
}

DOI: http://dx.doi.org/10.14718/CulturaLatinoam.2020.31.1.15

Trincheras de ideas valen más que trincheras de piedra.

José Martí

En Pensamiento político latinoamericano. Cultura, paz y poder, de Pablo Guadarrama (2019), el filósofo cubano expone nuestro pensamiento político americano en Amerindia (incas, mayas, aztecas, chibchas, etc.), en el periodo escolástico que domina en la Colonia, en el periodo ilustrado precursor de la independencia y en las tendencias políticas posteriores a la independencia que llegan hasta nuestros días, y lo articula con amplias y profundas reflexiones sobre la cultura y la paz. En efecto, la cultura es una condición de la paz y la paz una condición de la cultura. Y, como en toda su obra, sobresale la perspectiva humanista: el humanismo práctico latinoamericanista. El humanismo debe basarse en la identidad y la diferencia.

\footnotetext{
* Ph.D. en filosofía en la Universidad Javeriana de Bogotá. Ha sido catedrático de humanidades y filosofía en la Universidad de Puerto Rico y director del Departamento de filosofía de la misma universidad.
}

Referencia: Rojas Osorio, C. (2020). Pablo Guadarrama: el Pensamiento Político Latinoamericano y la Cultura de la paz. Cultura Latinoamericana, 31 (1), pp. 377-392. DOI: http://dx.doi.org/10.14718/CulturaLatinoam.2020.31.1.15 
Las prácticas políticas de los incas han sido consideradas por algunos como de tipo socialista por el énfasis en el trabajo colectivo, la distribución de la tierra y el importante papel del Estado. Fray Alonso de la Veracruz fue uno de los cronistas que sintió mayor estima por las instituciones políticas de los aztecas. Se dio cuenta que tenían un gobierno bien organizado, leyes y penalidades para los malhechores. Entendió bien por qué los pueblos originarios se enfrentaron bélicamente a los conquistadores. Fray Bartolomé de las Casas habla del "maravilloso gobierno" de los aztecas. Y afirma que "vivieron en paz y justicia". Los mayas tenían prácticas rotativas del poder: "La concepción republicana que sostienen Las Casas y Fray Alonso de la Veracruz enfatiza el origen y el control del poder soberano en el pueblo y por ello es necesario fortalecer los gobiernos locales frente a los centrales" (p. 70).

Guadarrama también afirma que "El reencuentro con el mundo precolombino constituyó una de las vías de construcción del humanismo latinoamericano. No es posible humanismo alguno en estas tierras que no haya partido de ese presupuesto" (p. 128). En el periodo de la Ilustración latinoamericana, el mexicano fray Servando Teresa de Mier sobresale en el pensamiento político, pues contribuyó al cuestionamiento del poder político español y del poder ideológico de la Iglesia católica aunada al poder político. El poder político de España en Latinoamérica está destinado a desaparecer. Defiende que la tierra pertenece a nuestros pueblos originarios por "ley natural" y no a las instituciones coloniales que los españoles han creado para usurpar la propiedad originaria. Denunció los extraordinarios privilegios de la Iglesia católica, y en especial sus privilegios económicos:

Todos los ilustrados latinoamericanos contribuyeron conscientemente o no, a la fermentación ideológica desalienanadora, la cual propiciaría a inicios del siglo XIX a la manifestación del poder político de las instituciones coloniales, como premisas indispensables para alcanzar niveles superiores de realización del humanismo en estas tierras. (p. 134)

El ecuatoriano Francisco de Santacruz y Espejo fue un avanzado modernista y defensor del pensamiento científico al estilo de Goethe, Humboldt, José Celestino Mutis y Francisco José de Caldas. Fue amigo del neogranadino Antonio Nariño y comulgaron en sus ideas independentistas. Nariño estimuló la necesidad de la educación de las nuevas generaciones de modo que dejaran atrás las arbitrariedades del Medioevo y progresaran hacia la libertad y 
la igualdad que la Ilustración promueve. Espejo estuvo exiliado en Bogotá y fue en Colombia donde más se difundieron sus ideas: "Tal vez puede ser considerado uno de los ilustrados que mayor sintetizan los rasgos distintivos de la Ilustración latinoamericana” (p, 135). Arturo Andrés Roig habla del socratismo de Espejo por su interés en el conocimiento de sí mismo y el afirmarse a sí mismo como un ser humano valioso. El pensamiento humanista latinoamericano ayudó a desprenderse de la tutela religiosa y, con ello, a preparar las condiciones ideológicas del proceso de liberación que se avecinaba. La vida de los pueblos originarios de América fue un motivo importante para el desarrollo de las utopías. El marino Rafael le relata la vida de una isla caribeña que Tomás Moro convierte en el lugar de la utopía. Y los relatos de viajes le sirvieron a Miguel de Montaigne para sus reflexiones sobre los supuestos bárbaros.

Durante el periodo ilustrado en Cuba, Félix Varela defendió la independencia, la abolición de la esclavitud y la humanidad de los habitantes de nuestros pueblos originarios. Es una cima de las ideas humanistas en el Caribe hispano. José de la Luz y Caballero se refirió al progreso en la historia en la dirección hacia la libertad. La Ilustración latinoamericana favorece el estudio de la lengua española en contra del latín, que era la lengua de la escolástica.

En Perú se seguía discutiendo acerca de la humanidad del indio. Los conservadores seguían la tesis de Ginés de Sepúlveda acerca de la inferioridad del indio. La lucha por la igualdad humana no estaba, pues, distanciada de intereses políticos:

La ilustración latinoamericana no se caracterizó desde el inicio por su radicalismo, sino por el reformismo, pero el propio proceso político independentista del cual era ella un preludio necesario, la impulsó a asumir ideas y proyectos de mayor envergadura que desbordaron los límites del pensamiento reformista en relación no solo con el poder político, sino con otras instituciones coloniales”. (p. 172)

Aunque bajo inspiración europea, la ilustración latinoamericana tuvo problemas específicos como la humanidad del indio, la abolición de la esclavitud, la superación de la escolástica aun reinante en nuestros centros de enseñanza, y la importante contribución ideológica a la lucha por la independencia. Durante el periodo ilustrado se desarrollaron distintas tendencias filosóficas como el liberalismo, el socialismo, el anarquismo; tendencias que coadyuvaron a la preparación de la lucha por la independencia nacional. 
Guadarrama dedica un capítulo al tema de la soberanía y la emancipación política en la independencia latinoamericana. La soberanía no debe entenderse solo en el sentido político, sino también económico y cultural. La idea tradicional rezaba que el soberano era solo Dios, pero se comenzó a cuestionar la soberanía del rey y poco a poco se fue transitando hacia la idea moderna de la soberanía del pueblo. Asimismo, la integración de nuestros pueblos estuvo siempre presente en la idea de soberanía, así lo vieron Bolívar, Miranda, Martí y Hostos: "En las colonias latinoamericanas la lucha por la soberanía se convertiría en el tema central de la mayor parte de sus más auténticos pensadores y líderes políticos, aun cuando no lo expresaran en esos términos" (p. 179).

La revolución haitiana fue el inicio de la independencia latinoamericana. Con frecuencia se subestima este acontecimiento trascendental. Napoleón quedó espantado cuando le presentaron la constitución de Haití, pues vio en ella un desafío a la unidad de la República de Francia. Haití se convertía en ejemplo para todas las colonias españolas. Las logias masónicas participaron en la lucha independentista. como se muestra en Bolívar, Martí, Miranda, Hostos, Betances. Los francmasones lucharon por gobiernos republicanos y democráticos.

Gabino Barreda, en México, dice que el dogma de la soberanía del pueblo se afirmó en Holanda en su lucha contra el dominio español, y fue apoyado por los enemigos de España, Inglaterra y Francia. Cuestionada la soberanía del rey, se entendió entonces que la soberanía radicaba solo en el pueblo. Francisco Miranda fue admirador de la revolución francesa y de la guerra de independencia de las trece colonias norteamericanas. Se ha pretendido que Simón Bolívar fue el fundador del partido conservador. Para ello se han fijado, sobre todo, en la Constitución de Bolivia que él redactó. Pero ese fue un momento de transición. Ante la debilidad de nuestros gobiernos y las luchas fratricidas, él vio la necesidad de fortalecer el ejecutivo. Por eso, también se pronunció contra el federalismo, no por principio, sino dada las circunstancias y por ser un "instrumento poco eficaz para mantener la paz y refrenar la fragmentación en facciones interna” (p. 198). Bolívar criticó la imitación de las constituciones europeas, pues con esa mímesis solo construimos "repúblicas aéreas".

Las oligarquías latinoamericanas han dominado el desarrollo político latinoamericano. Después de la independencia se necesitaba mantener vigente las instituciones democráticas y republicanas. Si la guerra de independencia fue difícil, no menos difícil fue mantener el 
derrotero democrático republicano. Andrés Bello abogó por el mejor estudio de las ciencias de la legislación: "La ecuación entre soberanía y emancipación se fue consolidando tras el proceso independentista, aun cuando las amenazas de las nuevas potencias imperiales y neocoloniales no se redujeron a palabras, sino que lamentablemente muchas de ellas se ejecutaron" (p. 215) La construcción de la soberanía se realiza mediante un largo proceso: "El pensamiento político desplegado a partir de las luchas por la independencia contribuyó a que se consolidara la identidad latinoamericana en confrontación con los amenazantes nuevos poderes imperiales" (p. 216).

\title{
El poder de las instituciones políticas
}

La copia de las instituciones exige siempre un reacomodo. Parecería que es mejor cambiar las instituciones desde dentro. Pero, en realidad, no siempre este es el caso:

\begin{abstract}
Una institución consiste en una entidad que aspira a regular algunas relaciones sociales mediante normas y establecimientos, con un objetivo determinado y responde a intereses de determinados sujetos, por lo que siempre expresa algún tipo de ideología, aunque en la mayoría de las ocasiones se presentan como instancias mejoradoras de representatividad universal”. (p. 220)
\end{abstract}

La modernidad ha cumplido un proceso de secularización, es decir, transformación de un enfoque que miraba desde una perspectiva divina a una voluntad política del ser humano. Manuel Castells destaca que la asociación es el proceso fundamental de una colectividad. El Estado de Derecho supone la división de poderes. La historia de la política se ha caracterizado por ciclos de revoluciones, la mayor parte de ellas fracasadas. Las actitudes miméticas no se corresponden con las necesidades de cada nación. Juan Bautista Alberdi destaca la necesidad de que la filosofía tenga, entre nosotros, un carácter político, una "(...) vinculación a los problemas concretos de nuestros pueblos" (p. 236). Las instituciones son instrumentos de poder. Parecería que el ser humano debiera disminuir las instituciones y su inmenso poder; pero no parece ser este el caso, pues alguna necesidad hay de ellas. Para Ángel Rama hay dos clases de intelectuales, los afectos al poder y los que lo resisten. Simón Rodríguez es ejemplo de resistencia al poder. 
Las instituciones no son neutrales: "Todas las instituciones expresan algún modo de enajenación, pues siempre sus poderes se revierten, directa o indirectamente, contra sus propios creadores" (p. 241). La institución política por excelencia es el Estado. Pablo González Casanova defiende que el Estado es el poder de la economía. Los sistemas políticos están determinados desde el Estado y las relaciones de poder que fijan la distribución del excedente. "La política podría caracterizarse como el uso limitado del poder social", según la idea de R. Goodin y Hans Kingelmann. Es decir, se trata en la política de las estrategias limitadas que se usan para el control del poder social. Las instituciones políticas subsumen a todas las demás instituciones sociales.

En el período de lucha por la independencia prevalecieron ideas radicales como las de Rousseau; en cambio, con el establecimiento de las repúblicas latinoamericanas, estas se caracterizaron mejor por el reformismo evolucionista: orden y progreso. Benito Juárez pensó que “(...) cada pueblo tiene el gobierno que se merece". "El afianzamiento del ideario democrático esta fuera de duda" (p. 256). El neoliberalismo no es amigo de la democracia. El socialismo es más amigo de la democracia. Las insuficiencias de la democracia solo se superan con más democracia. Tanto Martí como Bolívar insistieron en la necesidad de la educación para fortalecer la democracia.

\section{Cultura latinoamericana, identidad y autenticidad}

El jesuita José de Acosta, quien visita el Perú en el siglo XVI, valoró altamente las instituciones políticas o repúblicas de los incas, se opuso a que los indios fueran esclavizados y consideró que no era justo hacerles la guerra.

Guadarrama resalta la figura del venezolano Andrés Bello: "Era partidario de estimular la autonomía cultural de las repúblicas hispanoamericanas, propiciadoras de su identidad y autenticidad" (p. 273). Bello creó un código civil para Chile, y fue reproducido en los demás países latinoamericanos. Se opuso a los positivistas y defendió la necesidad de conservar valores culturales de la tradición hispánica. Para Bello, una ruptura radical no era posible. Según Scocozza, no cometió el error de trasplantar ideas que parecían muy avanzadas a un país que arrastraba una fuerte herencia colonial: “(...) confiaba extraordinariamente en el papel de la educación y la promoción cultural de los valores de cada pueblo" (p. 276). Bello luchó siempre por 
la independencia cultural latinoamericana. Pensaba que la integración latinoamericana era posible e importante para lograr el equilibrio del mundo, como lo pensaban Bolívar y Martí. En cambio, Sarmiento defendió un universalismo abstracto. Martí y Rodó criticaron su nordomanía: "José Martí se percató de las tremendas consecuencias que podría traer una asimilación de la cultura europea, y llamó la atención sobre cuáles serían los parámetros básicos y los puntos de orientación de la cultura latinoamericana" (p. 284). Martí no pensaba la cultura como algo libresco y meramente académico, pues incluía siempre la cultura popular. Se dio cuenta de que emergían nuevas formas de colonialismo y de imperialismo. El gran desafío era dar una solución adecuada a la cuestión social. Reclamó la unión de todas las fuerzas revolucionarias, tanto de Cuba como de toda América. Martí estuvo muy consciente de la dialéctica cultural entre lo universal y lo particular. Tenía claro que América viene de sí misma, y no de Washington o Rousseau. No piensa solo en Cuba y Puerto Rico, sino en toda nuestra América. Hay un internacionalismo martiano que tiene dimensiones planetarias. Fernández Retamar tenía mucha razón cuando consideró a Martí un tercermundista.

Dentro de un concepto fundado en el materialismo histórico, Guadarrama nos ofrece su idea de la cultura:

(...) grado de dominación por el hombre de las condiciones de vida de su ser, de su modo histórico concreto de existencia, lo cual implica de igual modo el control sobre su conciencia y toda su actividad espiritual, posibilitando mayor grado de libertad y beneficio a su comunidad. (p. 310)

Guadarrama cita a Gabriel García Márquez, para quien la cultura es el aprovechamiento social de la inteligencia humana. El filósofo cubano agrega a su definición de cultura la pregunta por lo que pueda significar autenticidad cultural:

Auténtico es un producto cultural, material o espiritual, que se corresponde con las exigencias de una comunidad humana histórica con el objetivo de mejorar sus condiciones de existencia, independientemente de que implique la imitación o reproducción de lo elaborado en otras comunidades”. (p. 311)

Dilema entre cultura universal o latinoamericana. No se pueden ignorar las fuentes exógenas de la cultura latinoamericana. José Enrique Rodó criticó la nordomanía, y así continuó la labor de Bolívar y 
de Martí. Para Rodó cada ser humano es el artífice de su propio destino. Pedro Henríquez Ureña cuestionó el europeísmo, y en especial la nordomanía de Sarmiento. El dominicano universal fue un gran estudioso de la cultura latinoamericana y puso una "marcada atención a la problemática de la identidad y la autenticidad latinoamericana" (p. 319). Jorge Luis Borges lo calificó de "maestro de América". También fue crítico del capitalismo. La utopía es una meta de nuestra América, "el ideal de justicia está antes que el ideal de cultura". Es en nuestra América donde deben fructificar las utopías.

El antropólogo cubano Fernando Ortiz estudió las raíces africanas de la cultura cubana. El mejoramiento de la humanidad está, sobre todo, en la cultura. La ignorancia solo favorece a las tiranías: "Confiaba en la función desalienadora de la educación y de la cultura, y en particular del derecho" (p. 323). La cultura nos hace fuertes. El mexicano José Vasconcelos arraiga su obra en la cultura mexicana. Apoyó los cambios educacionales del gobierno de Lázaro Cárdenas. Los pueblos latinoamericanos configuran una raza cósmica porque en ellos confluyen africanos, asiáticos y europeos: "Por su raza hablará el espíritu”. Para Guadarrama, Vasconcelos "constituyó una propuesta superadora del eurocentrismo y el universalismo abstracto de Sarmiento" (p. 325). Construye una filosofía universal pero desde su raíz mexicana. El destino de los blancos ha sido maquinizar el mundo. La cultura indígena tiene como derrotero la creación de una civilización latina. Para Guadarrama, la tesis de la raza cósmica estuvo viciada de idealismo, y "presuponía en cierto modo disolver todas las culturas nacionales y regionales en una sola unidad" (p. 326).

El mexicano Vicente Lombardo Toledano considera que "la cultura es un efecto más que una causa, es expresión de un momento determinado, pero cuando merece el nombre de tal, es expresión de un momento creador para beneficio perpetuo de los hombres por venir" (p. 327). En México hubo enfrentamientos entre los marxistas y los espiritualistas (Antonio Caso, Samuel Ramos, José Vasconcelos), pero dicha confrontación fue extralimitada "y unilateral al no apreciar propuestas valiosas de aquellos pensadores latinoamericanos” (p. 327). El peruano José Carlos Mariátegui considera necesario participar de la cultura universal pero sin que Latinoamérica sacrifique sus propios valores. Sin embargo, a juicio de Guadarrama, destacaba demasiado lo universal para saber apreciar la filosofía latinoamericana, pues no la reconocía. De todos modos, hizo análisis apropiados de la cultura peruana y latinoamericana destacando el componente indígena y mestizo. 
Aníbal Ponce defendió un humanismo práctico y urgía por un nuevo tipo superior de cultura, que ya veía en el socialismo soviético. Juan Marinello estaba bien consciente de la dialéctica cultural entre lo universal y lo particular. Apreció la dimensión universal del pensamiento y la obra de José Martí "por haberse correspondido auténticamente con la especificidad de su circunstancia cubana y latinoamericana de fines del siglo XIX" (p. 329). Alejo Carpentier considera, con razón, que nuestra identidad es histórica, móvil, abierta a la unidad contradictoria con otras culturas: "Carpentier se propuso asumir el mundo latinoamericano en la forma literaria que él demandaba" (p. 331). El barroco americano es producto de nuestro mestizaje y es lo que lo hace latinoamericano. Nuestra cultura es auténtica ya desde Tenochtitlán. El colombiano Luis Eduardo Nieto Arteta destaca que en los procesos históricos se hallan presentes también valores intemporales e inespaciales. Defiende un enfoque materialista al entender la historia de las sociedades como la expansión de las fuerzas productivas. Criticó el acausalismo de ver solo la libertad en la historia y no las causas y leyes que rigen los procesos históricos y articuló su análisis histórico con el análisis filosófico.

\section{Filosofía de la liberación y teoría decolonial}

Es preciso reconocer a Leopoldo Zea como uno de los grandes precursores de la filosofía de la liberación. Zea reflexiona sobre la especificidad de la cultura latinoamericana. Fue un humanista y promotor de la paz entre los pueblos que cuestionó el logocentrismo que se pretendía imponernos. La filosofía no es cuestión solo de lo universal y eterno, sino también del compromiso histórico concreto. La historia ya no es solo de Occidente, sino historia mundial. Superar a Europa no es decadencia, sino acceder a una historia auténticamente universal. Ninguna cultura es más universal que otra. La emancipación de los países africanos y asiáticos significa también su incorporación a la cultura y la historia mundial. Zea logra trascender su propio pensamiento hasta llegar a una filosofía de la liberación y la defensa de la filosofía latinoamericana. Expresó siempre una admiración sincera por la revolución cubana y llegó a identificarse con los postulados del materialismo histórico. Zea habla de su proyecto asuntivo: “(...) ir más allá de la propia realidad, pero partiendo y contando con ella sobre su conocimiento experiencia" (p. 361). Aunque se imite a otras comunidades, cada cultura imprime su sello propio a sus creaciones espirituales y materiales: 
La obra filosófica de Zea estuvo dirigida a reivindicar el grado de universalidad que encierra la cultura latinoamericana, como cualquier otra de distintas regiones del mundo, para de ese modo refutar todo tipo de racismo, hegemonismo y centrismo cultural que afecte la visión genuinamente acertada de la cultura. (p. 363)

La filosofía de la liberación nace en Argentina en la década de los 70 del siglo pasado. Enrique Dussel, Juan Carlos Scannone, Mario Casalla, Arturo Andrés Roig, Horacio Cerutti Guldberg, Dina Picotti, Carlos Cullen, etc., constituyeron el núcleo inicial, pero en realidad hay grupos diferentes de la filosofía de la liberación. Dussel propuso la destrucción de todos los discursos filosóficos dominadores, o sea, de Europa y Norteamérica, incluyendo el marxismo-leninismo. Dussel supera su antimarxismo original, reconoce que la filosofía de la liberación tiene mucho que aprender de Marx y denuncia "la universalidad de las tecnologías transnacionales" (p. 367).

En la filosofía de la liberación hay una corriente ético-cultural constituida por Rodolfo Kusch, Carlos Cullen y Juan Carlos Scannone. Hay en ellos un análisis de la cultura con base antropológica y una exaltación de los valores de la cultura indígena latinoamericana. Para Carlos Cullen toda cultura es geocultura, es decir, enraizada en un suelo o ambiente determinado. En esta corriente hay una preferencia por la sabiduría popular entendida, sobre todo, desde el mito y la religión. La gran reserva de la sabiduría está en los pueblos.

Arturo Andrés Roig mantuvo una posición independiente dentro de la filosofía de la liberación que conserva los valores culturales de la historia del pensamiento latinoamericano: "Supo equilibrar las mediaciones entre lo específico y lo universal” (p. 375). Horacio Cerutti Guldberg también emerge del grupo inicial de la filosofía de la liberación "y ha criticado abiertamente las posiciones de sus sectores más conservadores y ambiguos” (p. 370). Cerutti Guldberg ha asumido una posición independiente con elaboraciones metodológicas propias muy útiles para el estudio cultural del pensamiento de Nuestra América. En su filosofía está muy presente el marxismo y el historicismo. Armoniza tanto lo universal como lo particular de cada cultura latinoamericana y hace un balance crítico de la filosofía de la liberación. El filósofo nicaragüense Alejandro Serrano Caldera también considera que lo universal se alcanza desde lo propio y la circunstancia concreta. Hay una dialéctica entre lo universal y lo particular de cada cultura. Para Raúl Fornet Betancourt la filosofía 
de la liberación intensifica la relación entre cultura y filosofía. De acuerdo con Héctor Samour, la filosofía de la liberación no ha logrado incorporarse a la praxis liberadora de América Latina ni acompañar críticamente prácticas de resistencia y emancipación realizadas por distintos movimientos. Guadarrama destaca el componente humanista de la filosofía de la liberación y reconoce que favorece "la propagación de concepciones muy avanzadas, especialmente en sectores estudiantiles universitarios" (p. 379). La teoría de la dependencia, la filosofía de la liberación y la teología de la liberación han sido tres corrientes de pensamiento político que han tenido reconocimiento universal.

Raúl Fornet Betancourt habla de una filosofía intercultural. Es necesario liberar la filosofía del yugo de la tradición occidental y transformar la filosofía en el reconocimiento de una pluralidad de filosofías que emergen desde contextos culturales diferentes. Esto incluye una valoración de las culturas y de la función de la filosofía. Fornet habla de una justicia epistemológica y cultural que acompaña la lucha por los derechos de cada pueblo a su autonomía. Resistencia a los peligros de la globalización y el posmodernismo. La globalización parece ser un nuevo colonialismo. Fornet crítica las llamadas culturas nacionales que pretenden reducir la diversidad a una unidad hegemónica.

La teoría poscolonial se desarrolla en la India por parte de algunos intelectuales que se enfrentan críticamente a la dominación británica, no solo en lo político, sino también en lo cultural e ideológico. El palestino Edward Said también asume la teoría decolonial. El gran precursor es el martiniqués Franz Fanon. Muchos neocoloniales estuvieron muy influidos por el posestructuralismo y el posmodernismo. Lander sostiene que con el colonialismo de la conquista de América se inició, también, una constitución colonial de los saberes, los lenguajes y los imaginarios. Aníbal Quijano caracterizó la colonialidad del poder, esto es, la colonización del imaginario de los colonizados, en el modo de producir los conocimientos. Walter Mignolo planteó la desobediencia epistémica contra la hegemonía de la globalización. Es necesario indisciplinar las ciencias sociales. Se muestra crítico con las epistemologías occidentales. Boaventura de Sousa Santos propone una epistemología del Sur. Guadarrama opina que "encierra el peligro de enfrentar el eurocentrismo desde otro tipo de externalismo etnocentrista o sociocentrista, aunque se declare que esa no es la intención" (p. 387). 


\section{Neoliberalismo ante el poder, la paz y la cultura globalizada}

Guadarrama comienza diferenciando entre liberalismo y neoliberalismo. Para ambos, el centro de atención es el interés individual por encima de cualquier institución social. Cualquier institución es bienvenida siempre y cuando respete el derecho a la propiedad privada. Ahora bien, el liberalismo "no implicaría una total despreocupación por los demandas de ciertos derechos sociales, como ha sido común en el caso del neoliberalismo" (p. 391). La Declaración de los Derechos del Hombre y del Ciudadano reconoce el aprecio a ciertas demandas de justicia social. El neoliberalismo, en cambio, muestra una gran indiferencia por los derechos sociales y económicos, y solo presta atención a los derechos políticos y jurídicos. El liberal John Stuart Mill considera que el ser humano es responsable de su conducta ante los demás, por más soberano de sí mismo que sea. En cambio, el neoliberalismo "le otorga menor significado a la interdependencia de los seres humanos, al considerar que la sociedad es una especie de jungla donde se impone la ley del más fuerte y la solidaridad queda relegada a un segundo plano" (p. 392). La ilustración impulsó el pluralismo y la variedad de ideas filosóficas, en cambio, el neoliberalismo defiende "el pensamiento único". Ignacio Ramonet considera que hoy vivimos de la vigilancia basada en soportes electrónicos. El neoliberalismo tiende a la homogeneización de la cultura. El teórico neoliberal Friedrich August von Hayek piensa que los derechos sociales se consideran prescindibles. El liberalismo conservaba aspectos del humanismo abstracto burgués, como el ideario de la revolución francesa basado en la libertad, la igualdad y la fraternidad. Con el capitalismo financiero los poderosos se "sintieron más poderosos al imponer leyes de manera totalitaria" (p. 398). Enrique José Varona y Bertrand Russell, formados en el ideario liberal, criticaron "la nueva forma monopolista de la explotación capitalista” (p. 398). El liberalismo, hijo de la Ilustración, fomentaba un pensamiento laico y hasta ateo; el neoliberalismo promueve, en cambio, el fundamentalismo religioso unido a un fundamentalismo político, con lo cual se olvidan posturas civilizadas que la humanidad había alcanzado: la secularización de la política, la autonomía de los pueblos, el derecho a ser juzgado según un debido proceso legal, el respeto a la soberanía, etc. La socialdemocracia adoptó la propuesta keynesiana del Estado de Bienestar (Welfare State): "Las oligarquías burguesas apoyan la democracia mientras les conviene y les favorece, pero cuando benefician a los sectores populares apoyan 
el totalitarismo y los golpes de Estado" (p. 400). El neoliberalismo ha ido abandonando las bases progresistas del liberalismo moderno y puede calificarse como un conservadurismo. La globalización favorece al neoliberalismo. Donald Trump enarbola la bandera del proteccionismo nacionalista. La globalización no es una ideología, sino "una fase del desarrollo social en el cual los factores económicos, tecnológicos, comunicativos, políticos y culturales — que algunos denominan posmodernidad - se han acelerado e integrado como nunca antes había sucedido, y afectan de algún modo a toda la población mundial” (p. 402).

De por sí la globalización no promueve la guerra, pero el neoliberalismo sí. Al capitalismo le interesan las cosas, las mercancías, no los seres humanos. La bomba de neutrón aniquila todo lo vivo, y deja intactas las cosas. El mercantilismo ha colonizado toda la vida humana. La belicosidad de los imperios se acrecienta en sus periodos de decadencia. Para Norberto Bobbio solo la paz con justicia merece ese nombre. El daño al medio ambiente no resiste a largo plazo, y ese largo plazo se va acortando. La globalización es resultado del desarrollo del capitalismo. El capitalismo, según M. Castells, abarca hoy todo el planeta. La globalización favorece más a los países capitalistas que al resto del mundo. El neoliberalismo no necesariamente trae la modernización y el progreso. Hoy se predica la desaparición del Estado-nación, una completa falacia. Y nada tiene que ver con la idea de Marx de la desaparición del Estado. El pensamiento único defiende la teoría según la cual no hay alternativa al capitalismo. Es la naturaleza de las cosas la que se impone, y el ser humano es egoísta e individualista por naturaleza.

\section{Socialismo, paz y cultura}

La propuesta moderna del socialismo fue superar el liberalismo y beneficiar, no solo a la burguesía, sino también a la clase trabajadora. El socialismo promovió una nueva cultura con valores humanistas y a favor de la paz. Lenin firmó el decreto de la paz. Los líderes latinoamericanos socialistas se han pronunciado a favor de la paz y en contra de la guerra. El capitalismo no puede prescindir de las guerras. Después de la caída del muro de Berlín, las guerras se han acrecentado: "Ningún proyecto socialista se debe imponer desde otro país" (p. 419). El fracaso del socialismo real tuvo algunas causas que hoy nos parecen evidentes: la excesiva planificación de la economía, la carrera 
armamentista, la eliminación de toda forma de competencia. Carlos Fuentes agregó que el fracaso estuvo en la eliminación de toda forma de crítica. De acuerdo a Daniel Bell, fracasó una forma del socialismo: el leninista. Pero el socialismo no ha fracasado. Adolfo Sánchez Vázquez nos dice que el socialismo sigue siendo una alternativa válida. El socialismo hoy debe favorecer la propiedad social, pero no confundirla con la propiedad estatal, y favorecer la distribución equitativa de la riqueza. El mercado puede jugar cierto papel, pero no convertirlo en la solución de todos los problemas, como pretende el neoliberalismo. $\mathrm{El}$ socialismo debe promover una democracia participativa. Rosa Luxemburgo defendía que sin democracia no hay socialismo y sin socialismo no hay democracia. El tema ecológico es hoy fundamental en las actuales luchas sociales y políticas.

\section{Posmodernismo}

Frederick Jameson advierte la necesidad de diferenciar entre el hecho histórico de la posmodernidad y las teorías que las sustentan: "Resistirse a admitir que esta época es posmoderna puede no ser muy aceptable" (p. 460) En América Latina se ha discutido mucho sobre el momento en que se incorpora a la modernidad. La modernidad trajo la secularización de la política, la ruptura entre la razón y la fe, con predominio de la primera, y la tecnociencia: "La posmodernidad se cuestionó la validez de que la historia tenga un sentido progresivo y lineal" (p. 461). Ser moderno, afirma Marshall Berman, es vivir en un mundo en el cual, como dijo Marx, "todo lo sólido se desvanece en el aire". Nietzsche cuestionó el igualitarismo a que tiende el mundo moderno: "Así, el discurso posmodernista evidenció la falacia de la igualdad, la fraternidad y el humanismo" (p. 462). Según el posmodernismo, se derrumbaron todas las grandes utopías. De todos modos, plantea Guadarrama, la modernidad ha traído valores que la civilización occidental ha gestado y promovido. Hoy, después de algunas décadas, ya no fulgura con tanto brillo el discurso posmodernista.

El mito fue proscrito por la modernidad, y hoy renace bajo distintas modalidades. El posmodernismo critica las teleologías de la historia. Tomás Maldonado opina que la modernización creó una hegemonía y un intervencionismo de Occidente en las periferias del mundo. Ser moderno es asegurarse de seguir el modelo nórdico. En América latina, según algunos, la modernidad llegó tarde. Todavía al 
lado de amplios desarrollos capitalistas hay formas precapitalistas de producción.

El posmodernismo tuvo una vida fugaz, pues no prestó atención a "alternativas válidas a las exigencias sociales" (p. 477). La malograda modernidad todavía debe resolver problemas para los que el posmodernismo no ofrece ninguna solución. La memoria histórica de las nuevas generaciones se muestra cada vez más débil y despreocupada. Del posmodernismo es positivo el cultivo de las diferencias, los disensos y las tolerancias. Mauricio González afirma que hay una "acentuada hostilidad del posmodernismo al socialismo” (p. 481). Guadarrama opina, con mucha razón, que "las utopías no fallecen nunca definitivamente, sobre todo cuando son concretas, es decir, realizables en algún momento" (p. 484). El posmodernismo es una forma de escepticismo y debe preocupar a los intelectuales de América Latina. Debe pasarse juicio sobre el énfasis del nihilismo, tan evidente en la retórica de Gianni Vattimo, y superar todo tipo de reduccionismo.

\section{Cultura y paz}

La paz es un valor político supremo. La cultura de la paz es hoy una utopía posible. Kant habla de la paz como esperanza y progreso que debemos acelerar. La violencia depende de las relaciones de poder. Ortega y Gasset afirma que la construcción de la paz es un esfuerzo cultural. Es preciso conocer los mecanismos y justificaciones de la violencia. Tanto la violencia como la paz son hechos culturales. José Martí hablaba de la fiera que hay en cada ser humano, pero destacaba que debemos buscar los medios para desarrollar lo mejor en nosotros por la educación y la cultura. Una auténtica cultura de paz exige cambios socioeconómicos y nuevas políticas de poder: "Una cultura de paz está en el deber de propiciar la conservación de la memoria histórica de aquellos procesos bélicos que han producido innumerables muertes y víctimas sobrevivientes desgarradas por el recuerdo de los sufrimientos" (p. 527).

Como acabamos de apreciar, el tema de la relación entre cultura y paz es amplia y profundamente desarrollado por Guadarrama en este libro. La cultura es una condición para la paz, igual que la educación, aunque es obvio que ellas solas no son suficientes. Contribuir a la educación y a la cultura es contribuir al mantenimiento de la paz. A su vez, el desarrollo y mantenimiento de la paz contribuye al desarrollo de la cultura. En el pensamiento político latinoamericano hay muchas 
expresiones que identifican las instituciones culturales y educativas como protagonistas de una cultura de paz. No es suficiente estimular la tolerancia, sino que es necesario también promover el respeto a los derechos humanos y a la vida democrática. Tampoco hay que homogeneizar por la fuerza lo que son auténticas diferencias culturales. En las culturas hay identidad y diferencia. No se puede absolutizar la diferencia. La sociedad civil, y no solo el Estado, está llamada a mantener una cultura de paz. Y dentro de la sociedad cabe una gran responsabilidad a los intelectuales, los artistas y los periodistas. La identidad cultural la gesta cada pueblo. Pero hay una dialéctica entre lo universal y lo particular de cada cultura, pues la humanidad se caracteriza por los procesos de transculturación. El capitalismo histórico se caracteriza por fomentar las guerras, ello por razones varias como la expansión territorial, la adquisición de oro, plata, petróleo y, también, la apropiación de esclavos.

Que la cultura sea una condición de la paz implica también que estemos dispuestos a promover transformaciones sociales necesarias. El desarrollo de la paz se relaciona con los poderes, y por eso es necesaria la división del poder como, bien ha establecido la teoría del Estado de Derecho. Comunidad: institución política por excelencia que ha hecho posible la convivencia y supervivencia del género humano. Esta obra de Pablo Guadarrama no es solo la excelente descripción del pensamiento político latinoamericano, sino también una luminaria que puede y debe guiar los derroteros a seguir en el presente y en el futuro con relación a la democracia, el socialismo y la cultura de la paz. 